\title{
P028: Examining the relationship between fluoroquinolone use and Clostridium difficile infections (CDI): a meta-analysis
}

\author{
MB Formanek ${ }^{1}$, L Herwaldt ${ }^{2}$, ML Schweizer ${ }^{3}$ \\ From 2nd International Conference on Prevention and Infection Control (ICPIC 2013) \\ Geneva, Switzerland. 25-28 June 2013
}

\section{Introduction}

The incidence of CDI has increased substantially during the past decade. C. difficile is now one of the most important causes of healthcare-associated infections. Antimicrobial use is the primary risk factor for CDI. Several small studies have assessed whether fluoroquinolones increase the risk of CDI more than other antimicrobials.

\section{Objectives}

To systematically review and evaluate all published studies on the relationship between fluoroquinolone use and CDI.

\section{Methods}

We performed systematic literature searches in PubMed, Wiley's Cochrane Database of Systematic Reviews (CDSR), Wiley's Database of Abstracts of Reviews of Effects (DARE), Wiley's Cochrane Central Register of Controlled Trials (CENTRAL), Scopus (including EMBASE abstracts), and http://ClinicalTrials.gov. We ran the searches on October 15, 2012 with no limits on date or language. We used a random-effects model to obtain meta-analysis summary estimates. After reviewing 431 article abstracts and reviewing 22 articles in detail, we pooled risk estimates from 17 independent study populations.

\section{Results}

When we pooled the crude data from all 17 studies in a random-effects model, fluoroquinolone use was significantly associated with a higher risk of CDI than other antimicrobials (pooled OR: 2.93; 95\% CI: 2.12, 4.05).
Twelve of 17 studies provided adjusted risk estimates. When we pooled the adjusted data, fluoroquinolone use remained a significant risk factor for CDI, albeit with a lower pooled OR (pooled OR: 1.71; 95\% CI: 1.48, 1.96).

\section{Conclusion}

Fluoroquinolone use was associated with increased risk of CDI compared with other antimicrobials. Antibiotic stewardship campaigns to limit to overuse of fluoroquinolones may decrease the incidence of healthcare-associated CDI.

\section{Disclosure of interest}

None declared.

\section{Author details}

'Epidemiology/CADRE, University of lowa College of Public Health/lowa City Veterans Affairs Medical Center, lowa City, IA, USA. ${ }^{2}$ Internal Medicine/Clinical Quality, Safety, and Process Improvement, University of lowa College of Medicine/University of lowa Hospitals and Clinics, lowa City, IA, USA. ${ }^{3}$ Internal Medicine/CADRE, University of lowa College of Medicine/lowa City Veterans Affairs Medical Center, lowa City, IA, USA.

Published: 20 June 2013

doi:10.1186/2047-2994-2-S1-P28

Cite this article as: Formanek et al:: P028: Examining the relationship between fluoroquinolone use and Clostridium difficile infections (CDI): a meta-analysis. Antimicrobial Resistance and Infection Control 2013 2(Supp) 1):P28.

\footnotetext{
${ }^{2}$ Internal Medicine/Clinical Quality, Safety, and Process Improvement, University of lowa College of Medicine/University of lowa Hospitals and Clinics, lowa City, IA, USA

Full list of author information is available at the end of the article
} 